\section{EREM 77/4}

Journal of Environmental Research Engineering and Management Vol. 77 / No. 4 / 2021 pp. 122-131 DOI 10.5755/j01.erem.77.4.29942
Integration of Shading Device and Semi-Circle Horizontal Light Pipe Transporter for High-Rise Office Building in Tropical Climate

Received 2021/10

Accepted after revision 2021/11

\title{
Integration of Shading Device and Semi-Circle Horizontal Light Pipe Transporter for High-Rise Office Building in Tropical Climate
}

\section{Christopher Yii Sern Heng}

School of Housing, Building, and Planning, Universiti Sains Malaysia, 11800 USM Penang, Malaysia

*Corresponding author: chrisheng@usm.my

The blooming of a deep open plan in office buildings is accelerated due to economic profit reasons. This hinders the utilisation of daylight despite having abundance of daylight in tropical climate. Although a light pipe (LP) provides a means to illuminate the deep interior of the space, non-uniform daylight distribution still occurs due to the high illumination contrast across the room. The integration of a shading device (SD) in a room with an LP offers a solution to create a uniform daylight distribution. In this study, daylighting performances of 5 different types of an SD with different angles were analysed through a computer simulation software, namely Integrated Environment Solution Virtual Environment. The simulation was done using overcast and intermediate sky with sun conditions. The results showed that all SD cases improved the daylight uniformity across the room. A horizontal Venetian blind with an angle of $+45^{\circ}$ and $-45^{\circ}$ showed the best qualitative performance among all the cases. However, further shading and illumination are needed respectively to increase the potential daylight utilisation in an open plan office room. This study also concluded that a vertical Venetian blind did not provide a good daylight uniformity due to the vertical nature of the SD. A design recommendation guide for building designers is proposed at the end of this study to promote the integration of an SD and an LP in deep open plan high-rise office building.

Keywords: light pipe, shading device, high-rise office, simulation, daylight uniformity. 


\section{Introduction}

Daylight is known to have a positive physiological and psychological impact towards humans, especially office workers (Hamedani et al., 2019; Wirz-Justice et al., 2020). It creates a healthier environment and thus increases the productivity and reduces absenteeism. Daylight also reduces heat generation for the same amount of the lighting level compared to electrical lighting. It helps to reduce the cooling load in a building as much as 15\% (Ander, 2003; Muhs, 2000).

Previous research has shown the outdoor illuminance of tropical climate such as Malaysia to be more than 20,000 lx throughout the working hours of 09:00 and 17:00 (Lim, 2019; Heng et al., 2020). This offers an opportunity to harvest this renewable energy resource in the tropical region (Sharifah and Sia, 2004).
A deep open plan, where the floor plans have a long depth and no partition or work cubicles in the middle, is a common design in current high-rise buildings due to the economic benefits through maximizing a rentable floor area (Hansen, 2006; Lashina et al., 2019). The depth of the deep floor plan exceeds twice the ceiling height (Ander, 2003). A deep plan building usually has a depth of more than $10 \mathrm{~m}$. These floor plans create visual discomfort in the form of glare due to the contrast lighting level between both the front and the end of the space. Previous studies have shown that the usage of a horizontal light pipe (LP) can provide an adequate illuminance level to the interior of the deep plan (Heng et al., 2020). However, the illuminance level between both ends of the space is still too stark as shown in Fig. 1.

Fig. 1. A contrasting illuminance level across a deep plan office with an $L P(1)$ and without an $L P(2)$

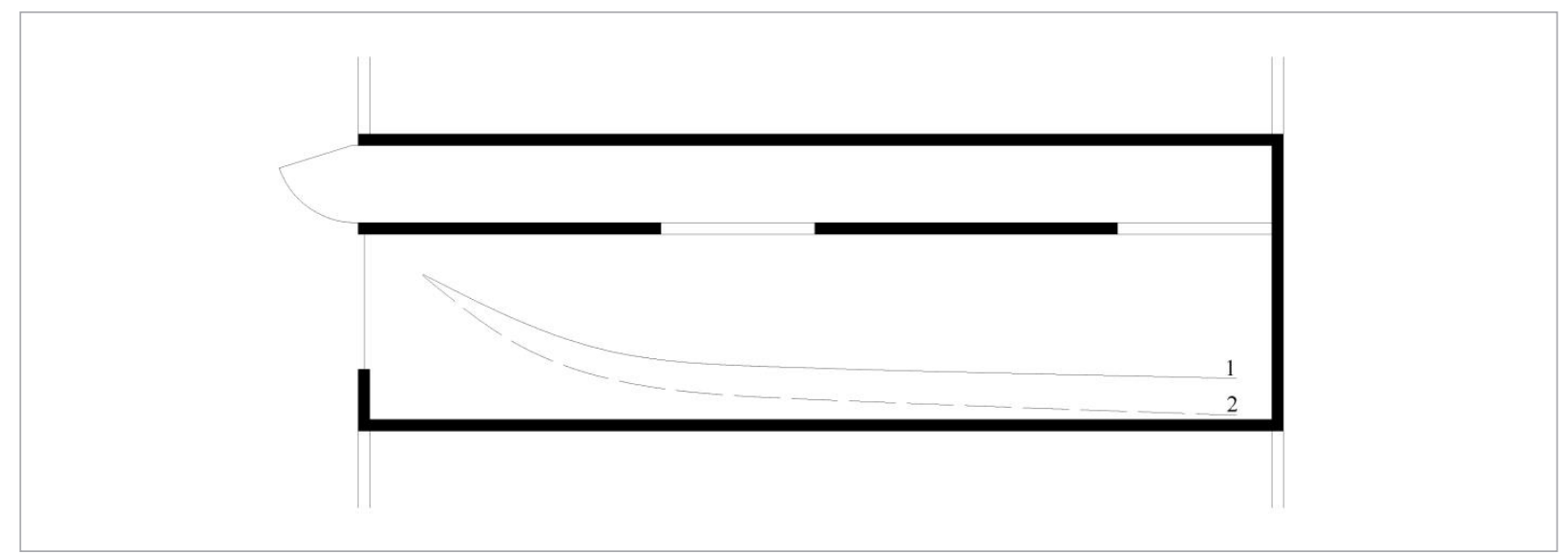

This paper proposes a daylight integration system between a light distribution system and a shading device (SD) in a deep open-plan high-rise office in a tropical region, specifically in Malaysia. The study uses computer simulation assistance to determine the daylight performance of the system.

A light distribution system and a shading device. Light distribution systems function to bring daylight into the deep area of a space. They are divided into two: a light guide system (LGS) and a light distribution system (LTS). The former can distribute daylight up to $10 \mathrm{~m}$ distance from the perimeter of a building while the latter can cover more depth (Hansen, 2006). Horizontal and vertical LPs are two types of a light transport system where they distribute daylight from the perimeter and the roof of a building into the interior. However, although a vertical LP has been studied before (Kocifaj and Petrzala, 2019; Sharma et al., 2018), it is not a feasible option to be used in a highrise office building because valuable space must be sacrificed to transport daylight from the rooftop to the spaces below. 
Excessive daylight in a space, especially at the perimeter, can be prevented by using an SD (Lim and Heng, 2016). Venetian blinds (VB), tinted glazing and a light shelf (LS) are some examples of the SD that can be used to provide shading and distribution of light. These SDs also help in reducing solar heat gain and discomfort glare which will influence the human comfort (Kunwar et al., 2020).

Previous research. Previous studies on the LP and the SD have largely focused on temperate and Mediterranean climates (Obradocis and Matusiak, 2020; Kocifaj and Petrzala, 2019; Wu et al., 2019). The findings from these studies may not be suitable to be applied in tropical climate due to the differences of global illuminance where, generally, tropical climate has a significantly higher value.

There are many studies done on the LP and the SD but most of the studies only reached up to a 6-7 $\mathrm{m}$ depth (Obradocis and Matusiak, 2020; Kocifaj and Petrzala, 2019; Wu et al., 2019; Lee et al., 2021). The studies on the LP have mostly emphasized the innovation of a collector and an extractor such as a laser cut panes, and egg crate reflector and a diffuser (Obradovic and Matusiak, 2020; Kocifaj and Petrzala, 2019; Elsiana et al., 2020). Studies on the SD such as an LS and VB focus on the automated system (Kunwar et al., 2020; We et al., 2019; Motamed et al., 2020). Furthermore, none of the studies have focused on the LP and the SD as an integrated system.

This paper is a preliminary study which evaluates the daylight uniformity and quantitative performance of types of the SD that is integrated into a horizontal LP in a deep open-plan high-rise office building in tropical climate. The LP has a semi-circle transporter and two extractor openings which have been shown to provide an optimum daylight utilization (Heng et al., 2020).

\section{Methods}

This study used computer software simulation, namely Integrated Environment Solution Virtual Environment (IESVE), as a tool to determine the performance of the integrated LP and various SDs. In
IESVE, a ray-tracing calculation method is employed to calculate the surface reflection, transmission, and refraction values using a radiation simulation engine. It can also create the geometric models required for this study. The software has been used and validated by several studies (Heng et al., 2020, Iversen et al., 2013; Mehta et al., 2017; Zune et al., 2020; Ramesh and Ramachandraiah, 2021).

Based on a previous study, the differences of a sky condition between an IESVE sky component and a tropical sky condition can be eliminated by using a daylight ratio (DR) (Heng et al., 2020). The calculation of the DR is shown in Equation 1.

$D R=\frac{\text { Work plane illuminance }}{\text { Exterior horizontal global illuminance }} \times 100 \%$

Simulation setup. In this study, a typical deep plan office room with dimensions of $6.0 \mathrm{~m} \times 12.0 \mathrm{~m} \times 2.7$ $\mathrm{m}$ was modelled in IESVE using Modellt function. The room is oriented to face south to enable daylight gathering throughout the day as the geographical location of Penang is above the Equator line. The room is attached to a semi-circle LP with a radius of $1.0 \mathrm{~m}$ as shown in Fig. 2. The values for reflectance, specularity and roughness of the internal surface are shown in Table 1.

Fig. 2. A base case model with a semi-circle light pipe

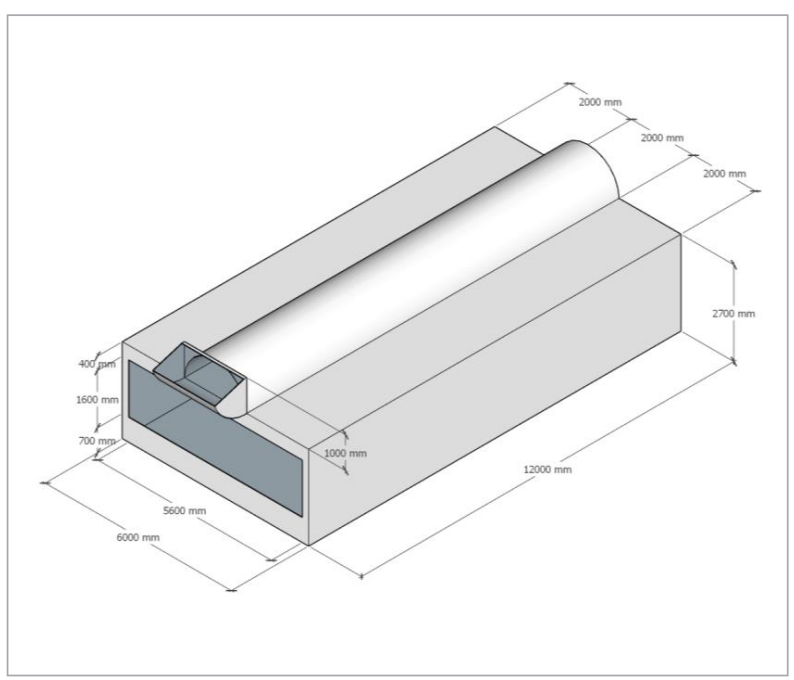


Table 1. Values for the internal surface properties

\begin{tabular}{c|c|c|c|c|c}
\hline Components & Reflectance (\%) & Specularity (\%) & $\begin{array}{c}\text { Roughness } \\
\text { Value }\end{array}$ & Type & Visible Transmittance (\%) \\
\hline Wall & 70 & 0.03 & 0.03 & Plastic & N/A \\
\hline Floor & 20 & 0.03 & 0.20 & Plastic & N/A \\
\hline Ceiling & 80 & 0.03 & 0.03 & Plastic & N/A \\
\hline LP (Inner surface) & 99 & 0.05 & 0.03 & Metal & N/A \\
\hline SD & 99 & 0.05 & 0.03 & Metal & N/A \\
\hline Glazing & N/A & N/A & N/A & N/A & 0.75 \\
\hline
\end{tabular}

The sky conditions that were used in this simulation are $10 \mathrm{k}$ lx overcast sky which represents the worst-case scenario and intermediate sky with sun. For the latter, three design days were employed which were $21^{\text {st }}$ of March, $22^{\text {nd }}$ of June, and $22^{\text {nd }}$ of December, with three different times, which were 09:00, 12:00, and 15:00.
Five configurations of a VB and an LS were used in the simulation software as shown in Fig. 3. The configurations were based on a different angle of each system (Table 2). The difference angle and the type of the SD will influence the shading of light and penetration of light into the space.

Fig. 3. Horizontal Venetian blinds $\left(+45^{\circ}\right.$ and $\left.-45^{\circ}\right)$, vertical Venetian blinds $\left(-45^{\circ}\right.$ and $\left.+45^{\circ}\right)$, and a light shelf

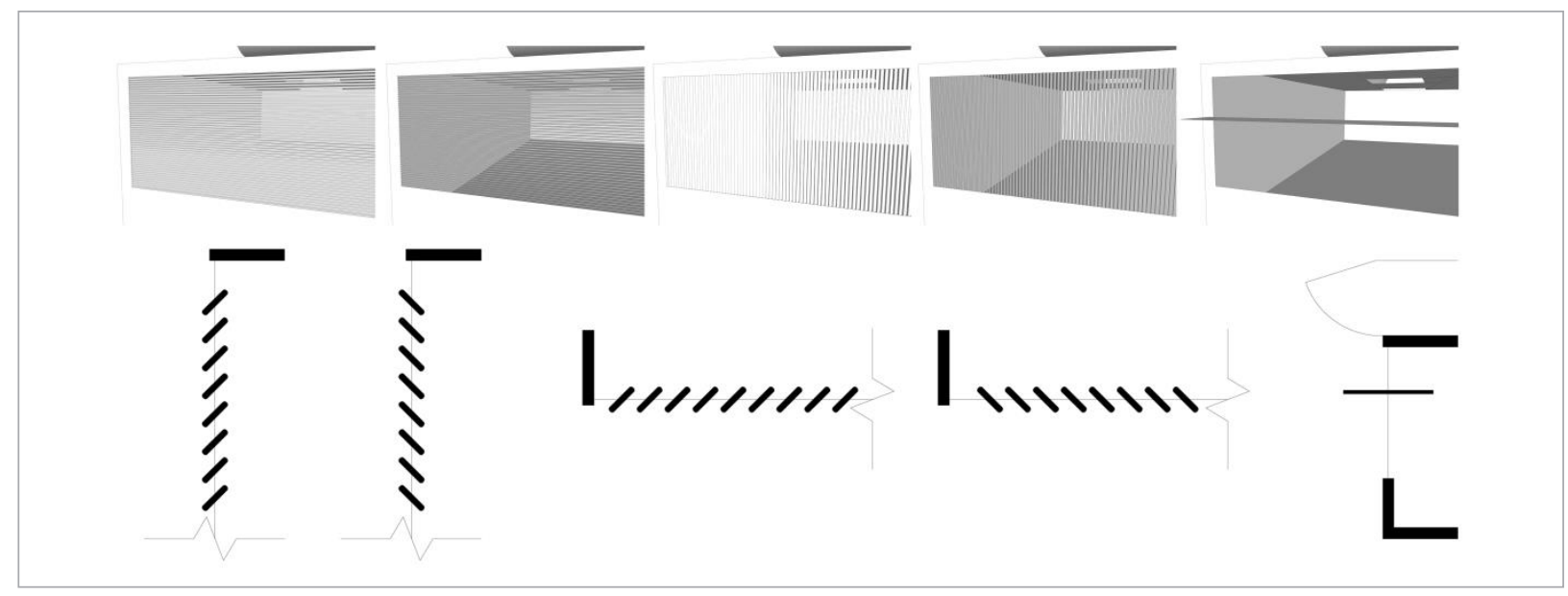

Table 2. Values for the internal surface properties

\begin{tabular}{c|c|c}
\hline Name & Components & Angle $\left(^{\circ}\right)$ \\
\hline BC & Base case & NA \\
\hline SD 1 & Venetian blinds (Horizontal) & -45 \\
\hline SD 2 & Venetian blinds (Horizontal) & -45 \\
\hline SD 3 & Venetian blinds (Vertical) & +45 \\
\hline SD 4 & Venetian blinds (Vertical) & 0 \\
\hline SD 5 & Light shelf & 0 \\
\hline
\end{tabular}


Criteria of analysis. The performance of each case was first evaluated using an average daylight factor (DF) to represent the worst-case scenario which was taken at $0.8 \mathrm{~m}$ above the floor to indicate the work plane level. The absolute illuminance level was then used to calculate the DR which was converted to estimated indoor illuminance (EII) using Equation (2). For the purpose of this study, the estimated exterior global illuminance values used at 09:00, 12:00, and 15:00 were 27,104 lx, 84,613 lx, and 74,991 lx (Heng et al., 2020). The uniformity of the work plane illuminance (WPI) was determined through the WPI ratio (WPIR), which was calculated using Equation (3).

Ell $=\frac{D R}{100} \times$ Estimated exterior global

horizontal illuminance $\times 100 \%$

$$
W P I R=\frac{E_{\min }}{E_{\max }}
$$

\section{Results and Discussion}

Daylight quantity performance. Fig. 4 shows the comparison of the DF between the base case and SD 1 to SD 5. The results showed that the SD generally decreased both the minimum and the maximum DF. The former ranged from $-71.43 \%$ to $-28.57 \%$ while the latter ranged from $9.29 \%$ to $-69.65 \%$. There were also huge reductions of the DF at row 1 to $4(-34.55$ to -92.11$)$ and row 1 to 8 ( -34.55 to -88.82$)$. SD 1 showed the lowest average DF with $0.40 \%$, followed by SD 3 and SD 4 with $1.21 \%$ and $1.27 \%$, respectively. The base case had the highest average DF with 2.95\%, followed by SD 2 with $1.98 \%$.

All the cases were analysed for 66 points in the room, and the percentage of DF points that falls in the recommended range of $1.0 \%$ to $3.5 \%$ according to MS1525:2014 (DSM, 2014) is shown in Fig. 5. Based on the results, the base case showed the highest percentage of DF points in the range with 28\%. SD 5 and SD 2 were the second and third highest percentage with $26 \%$ and $25 \%$, respectively. The base case had the highest percentage of DF points of more than $3.5 \%$ due to the high penetration of daylight near the room opening while the inclusion of an SD reduced the percentage value.

The Ell for the base case and five SD cases were obtained and calculated as shown in Fig. 6. Based on the results that are tabulated in Table 3, the average Ell at row 1 to 8 was lowered by $39.17 \%$ to $88.77 \%$ when the SD was integrated to the base case. The reduction of the average Ell was more evident at row 1 to 4 with a range of $40.86 \%$ to $91.54 \%$.

Fig. 4. DF performance of the base case and SD 1 to SD 5

\begin{tabular}{|c|c|c|c|c|c|c|c|}
\hline & & & & & & & \\
\hline & sults & $\mathrm{BC}$ & SD 1 & SD 2 & SD 3 & SD 4 & SD 5 \\
\hline $\begin{array}{l}\text { Simulated } \\
\text { Indoor } \\
\text { Illuminance }\end{array}$ & $\begin{array}{l}\text { LUX } \\
475 \\
425 \\
375 \\
325 \\
275 \\
225 \\
175 \\
125 \\
75 \\
25\end{array}$ & & (m) & & & & \\
\hline & Minimum & 0.28 & 0.08 & 0.17 & 0.13 & 0.12 & 0.20 \\
\hline & Maximum & 25.73 & 7.81 & 20.45 & 28.12 & 25.97 & 20.49 \\
\hline Daylight & \begin{tabular}{|l|} 
Row 1-4 \\
\end{tabular} & 8.88 & 0.70 & 5.81 & 3.67 & 3.90 & 5.39 \\
\hline & Row 1-8 & 5.01 & 0.56 & 3.28 & 2.04 & 2.16 & 3.13 \\
\hline & Average & 2.95 & 0.40 & 1.98 & 1.21 & 1.27 & 1.85 \\
\hline & Minimum & & -71.43 & -39.29 & -53.57 & -57.14 & -28.57 \\
\hline & Maximum & & -69.65 & -20.52 & 9.29 & 0.93 & -20.37 \\
\hline$\%$ or changes & \begin{tabular}{|l|} 
Row 1-4 \\
\end{tabular} & & -92.11 & -34.55 & -58.71 & -56.06 & -39.37 \\
\hline & Row 1-8 & & -88.82 & -34.55 & -59.29 & -56.82 & -37.44 \\
\hline & Average & & -86.44 & -32.88 & -58.98 & -56.95 & -37.29 \\
\hline
\end{tabular}


Fig. 5. Percentage of DF points in the range of $1.0 \%$ to $3.5 \%$

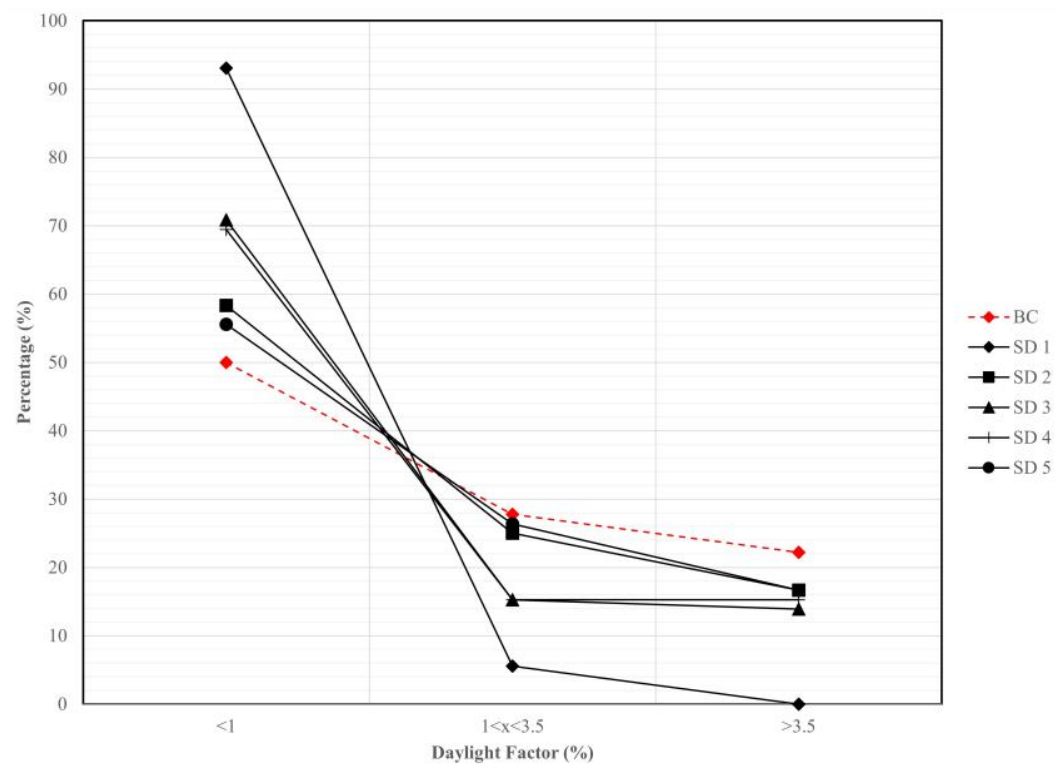

Fig. 6. The simulated Ell for the base case and SD 1 to SD 5
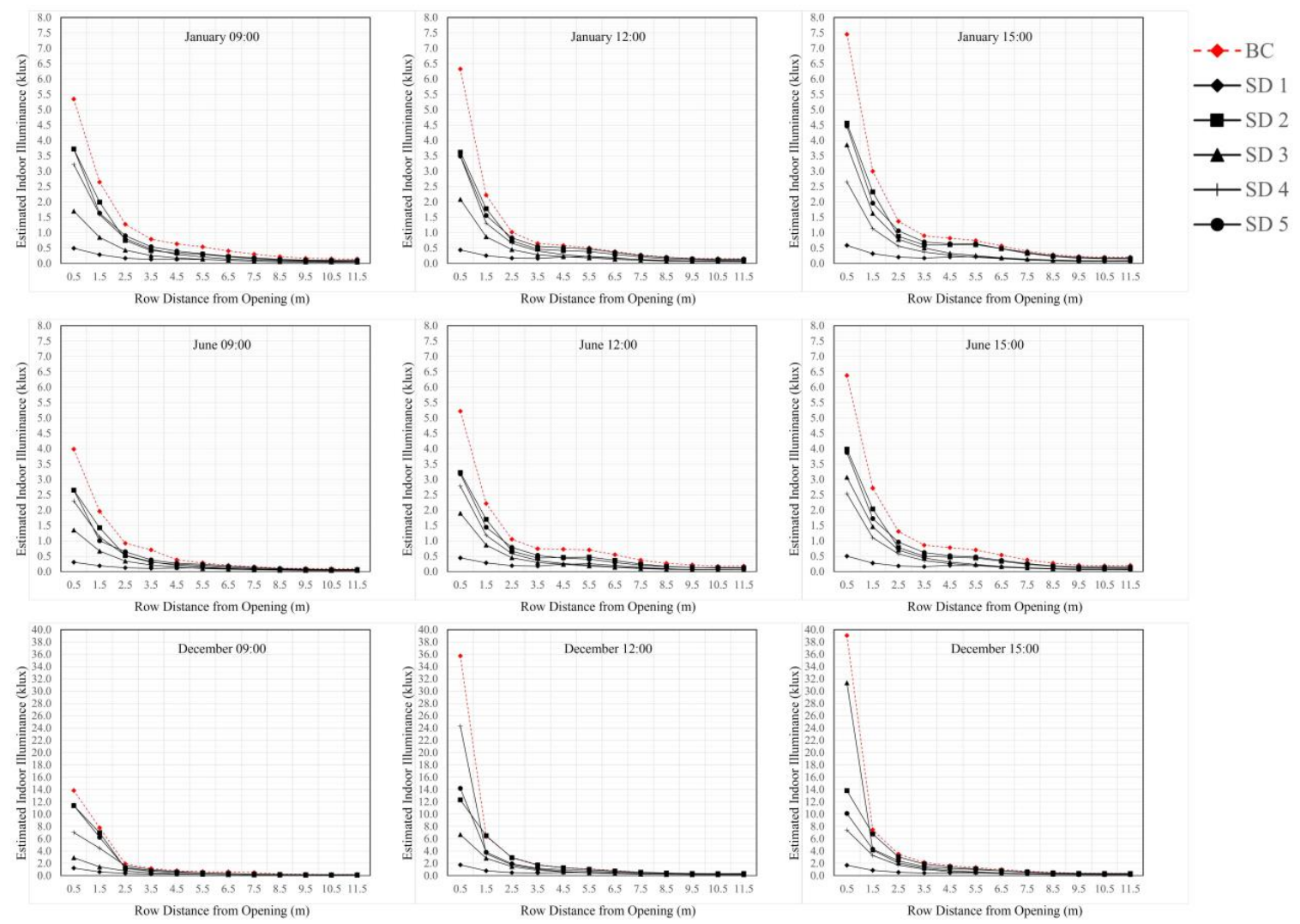
Table 3. The average Ell and percentage of points within 300-500 lx

\begin{tabular}{|c|c|c|c|c|c|c|c|}
\hline & \multirow{2}{*}{ Criteria } & \multicolumn{6}{|c|}{ Cases } \\
\hline & & BC & SD 1 & SD 2 & SD 3 & SD 4 & SD 5 \\
\hline \multirow{4}{*}{$\begin{array}{l}\text { Average } \\
\text { Ell }\end{array}$} & Row 1-4 (lx) & 5132 & 434 & 3035 & 2266 & 2459 & 2728 \\
\hline & $\begin{array}{l}\text { Percentage of } \\
\text { improvement (\%) }\end{array}$ & NA & 91.54 & 40.86 & 55.85 & 52.09 & 46.84 \\
\hline & Row 1-8 (lx) & 2883 & 324 & 1753 & 1250 & 1360 & 1591 \\
\hline & $\begin{array}{l}\text { Percentage of } \\
\text { improvement (\%) }\end{array}$ & NA & 88.77 & 39.17 & 56.64 & 52.80 & 44.82 \\
\hline \multicolumn{2}{|c|}{$\begin{array}{l}\text { Percentage of points within } \\
300-500 \text { lx (\%) }\end{array}$} & 14.97 & 10.34 & 15.90 & 9.26 & 10.03 & 15.28 \\
\hline
\end{tabular}

Referring to the same table, SD 2 had the highest percentage of points within the range of $300-500 \mathrm{~lx}$ (15.90\%), which is suitable for paper and computer work. The second highest percentage was achieved by SD 5 with $15.28 \%$.

Daylight quality performance. The average WPIRs for the base case and five SD cases are shown in Fig. 7.
Generally, all the SD cases have higher average WPIR than the base case, especially SD 3, SD 4, and SD 5. The performance of the base case is particularly poor in December due to the solstice that causes a high illuminance contrast. Nonetheless, the integration of any SD helps to improve the daylight quality on the interior.

Fig. 7. The average WPIR for the base case and SD 1 to SD 5

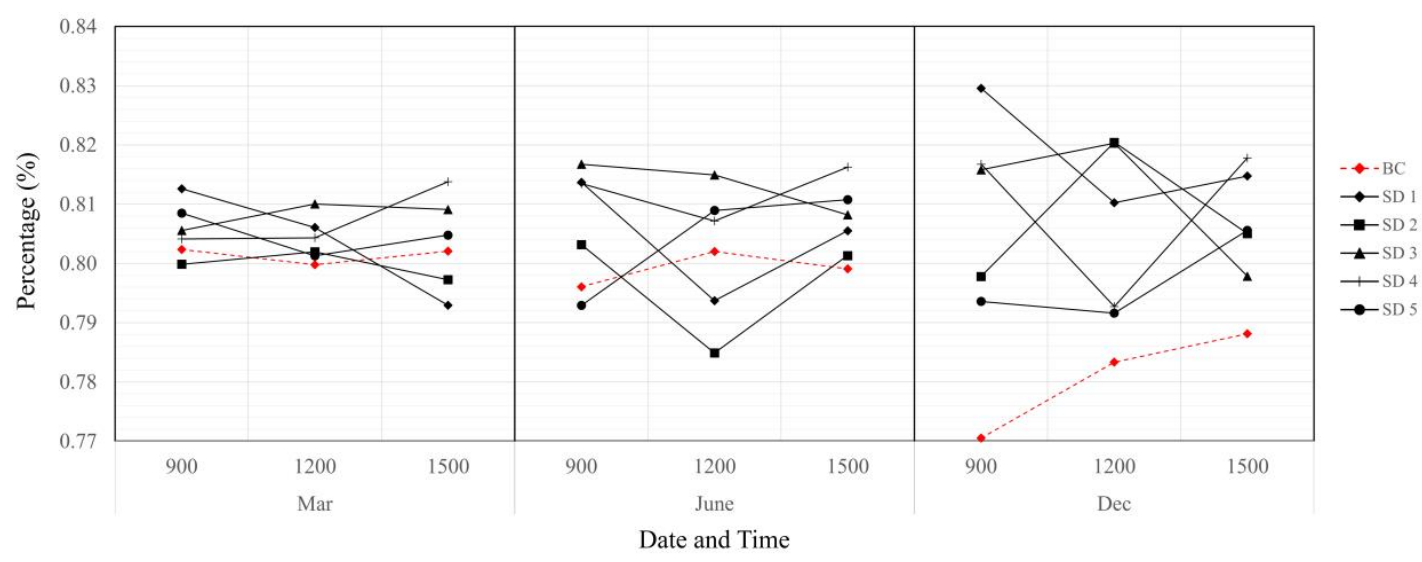

Fig. 8 shows the percentages of the WPIR that meet the acceptable benchmark of $E_{\text {min }} / E_{\text {max }}>0.5$ as recommended by Dubios (2001). Generally, all the SD cases have a higher percentage of meeting the benchmark compared with the base case except for two occasions while SD 1 has the overall highest percentage (96.03-100.00\%). A stricter benchmark of 0.7 was used to further examine the daylight uniformity level. SD 2 has the highest percentage of meeting the benchmark on three instances which are $22^{\text {nd }}$ of June 15:00 (80.95\%), $22^{\text {nd }}$ of December 12:00 (83.33\%) and 15:00 (80.95\%), whereas SD 1 and SD 5 have two instances each. Generally, SD 1 has the lowest percentage to meet the benchmark, especially in the months of March and June. 
Fig. 8. Percentages of the WPIR that meet the benchmark of 0.5 and 0.7
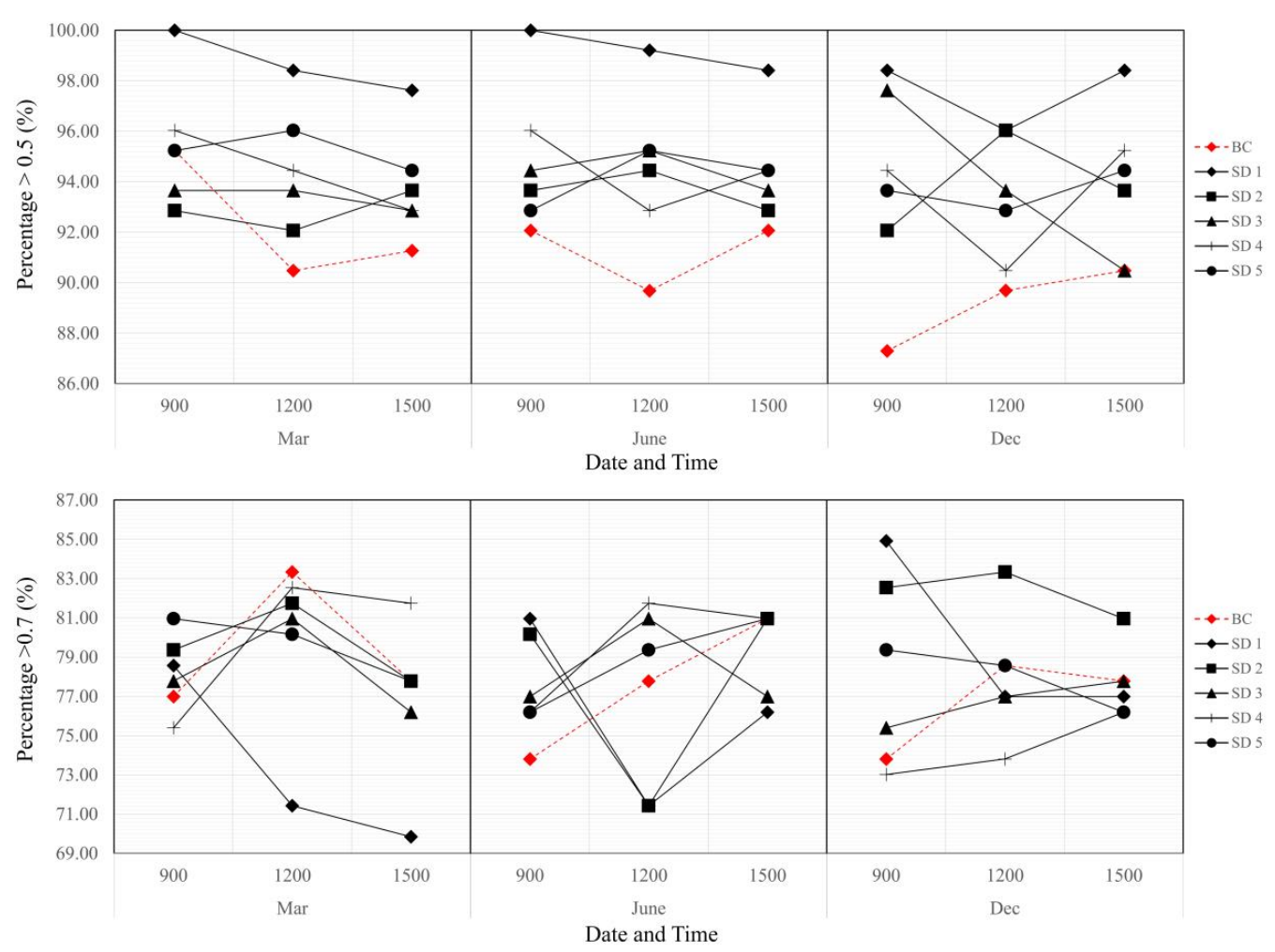

Discussion. Daylighting in a deep open plan office with tropical climate can be improved with the integration of the SD into a room with LP. As shown in Fig. 9, significant improvements up to $91.54 \%$ were noticed at the front area of the room. This creates an opportunity to utilise more daylight than is available in the room, thus reducing the dependency on electrical lighting.

Another advantage of using the SD and the LP were the ease of installation and the availability of the system which helped to decrease the overall procurement cost. Without the need for complicated installation methods, an SD can be retrofitted in an existing room while an LP can be installed in the plenum space above the ceiling alongside the wirings for the building services. Fig. 10 shows the guide to the findings of this study. Different SDs with angle variation yield different results for daylight quantity and quality. This summary guide can be used by building designers to determine the choice of the SD based on the lighting requirement for the space where SD 1 and SD
2 provided the best daylight quality overall but the former required more illumination at the rear end while the latter needed more shading at the front area of the room. On the contrary, SD 4 and SD 5 showed an average performance for all the three categories.

Fig. 9. Ell for SD cases and percentage of improvement against the base case

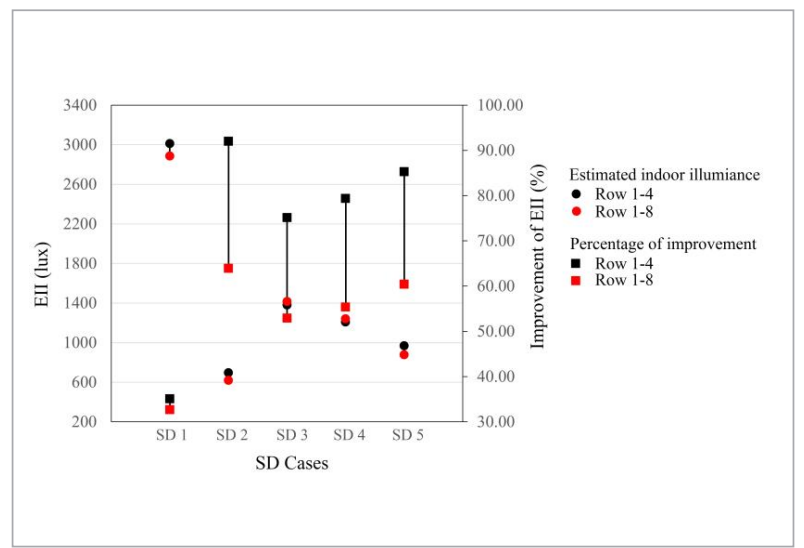


Fig. 10. Comparison of daylight quantitative and qualitative performance

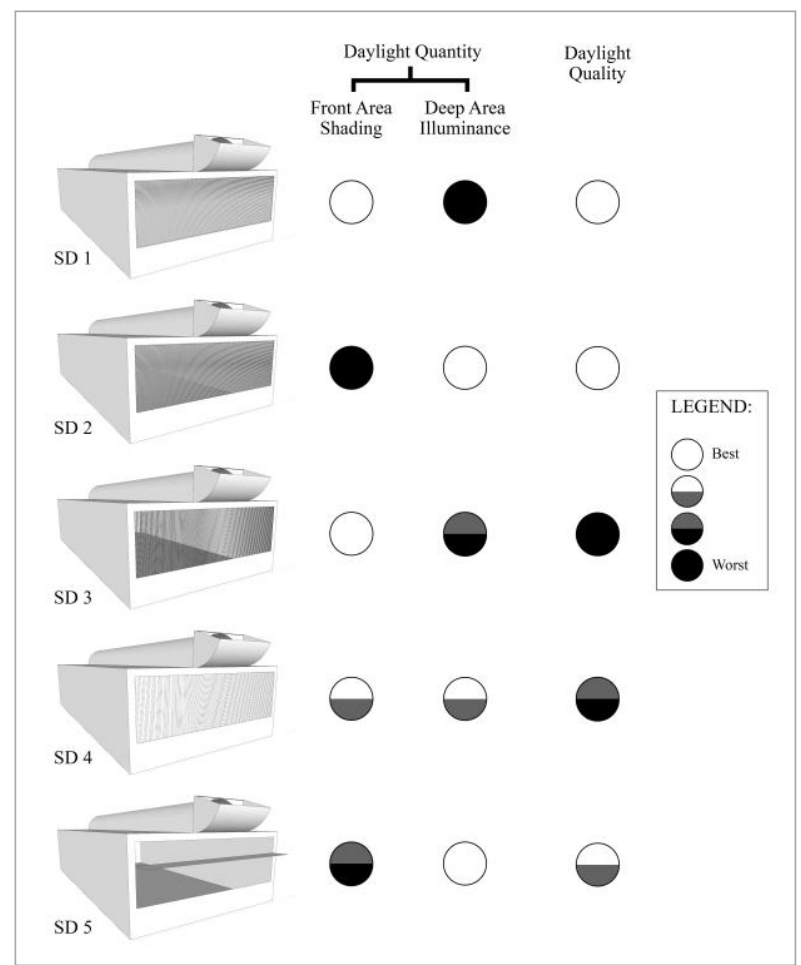

\section{Conclusions}

This research concludes by proposing usage of the integrated SD and LP to provide uniform daylighting in a deep open plan building in tropical climate. A horizontal VB with an angle of $+45^{\circ}$ (SD 1) and $-45^{\circ}$ (SD 2)

\section{References}

Ander, G.D. (2003). Daylighting Performance and Design. John Wiley and Sons Inc, New Jersey.

Department of Standards Malaysia, MS 1525, Malaysian Standard: Code of Practice on Energy Efficiency and Use of Renewable Energy for Non-residential Buildings, 1st Revision, 2014 (Malaysia).

Dubois, M.C. (2001). Impact of Solar Shading Devices on Daylight Quality: Simulations with Radiance. Research Report, Lund University, Lund, Sweden.

Elsiana, F., Soehartono, F., Kristanto, L. (2020). Daylight performance of horizontal light pipe with egg-crate reflector in was recommended to be integrated with a semi-circle LP which showed good daylight quantity and quality. However, additional studies to further improve the shading at the front area and the illumination at the rear end of the room are required.

A vertical VB did not provide a good daylight uniformity across the room as light can still penetrate through the vertical members of the VB. The lack of shading created a high contrast between the front and rear area of the room and, therefore, it was not suitable for potential daylight utilisation.

Furthermore, more building orientations such as north, east, and west can be tested to add robustness to the daylight performance guide on SD and LP integration. This can also be further enhanced by adding various VB and LS angles.

The potential energy savings with SD and LP usage require further investigation. The need for artificial lighting as well as cooling requirement for the heat production needs to be considered too.

Future research on the office worker's satisfaction can be conducted through questionnaires to observe and evaluate user's perception towards the lighting level in the space.\{Gurauskiene, 2006, Eco-design methodology for electrical and electronic equipment industry\}

\section{Acknowledgements}

The author would like to acknowledge research funding from Short Term Research Grant, Universiti Sains Malaysia (304/PPBGN/6315590).

the tropics. IOP Conference Series: Earth and Environmental Science 490, pp. 1-12. https://doi.org/10.1088/17551315/490/1/012006

Hamedani, Z., Solgi, E., Skates, H., Hine, T., Fernando, R., Lyons, J., Dupre, K. (2019). Visual discomfort and glare assessment in office environments: a review of light-induced physiological and perceptual responses. Building and Environment, 153, p. 267280. https://doi.org/10.1016/j.buildenv.2019.02.035

Hansen, G.V. (2006). Innovative Daylighting Systems for DeepPlan Commercial Buildings. PhD Thesis, School of Design, Queensland University of Technology. 
Heng, C.Y.S., Lim, Y.W., Ossen, D.R. (2020). Horizontal light pipe transporter for deep plan high-rise office daylighting in tropical climate. Building and Environment, 171, p. 106645. https://doi. org/10.1016/j.buildenv.2020.106645

Iversen, A., Roy, N., Hvass, M., Jørgensen, M., Christoffersen, J., Osterhaus, W., Johnsen, K. (2013). Daylight Calculations in Practice: An Investigation of the Ability of Nine Daylight Simulation Programs to Calculate the Daylight Factor in Five Typical Rooms.

Kocifaj, M., Petrzala, J. (2019). Designing of light-pipe diffuser through its computed optical properties: a novel solution technique and some consequences. Solar Energy 190, p. 386-395. https://doi.org/10.1016/j.solener.2019.08.046

Kunwar, N., Cetin, K.S., Passe, U., Zhou, X., Li, Y. (2020). Energy savings and daylighting evaluation of dynamic venetian blinds and lighting through full-scale experimental testiselfng. Energy 197, p. 117190. https://doi.org/10.1016/j.energy.2020.117190

Lashina, T., Vleuten-Chraibi, S.V.D., Shrubsole, M. P., Rosemann, A., Loenen, E. V. (2019). A comparison of lighting control strategies for open offices. Building and Environment 149, p. 68-78. https://doi.org/10.1016/j.buildenv.2018.12.013

Lee, H., Zhao, X., Seo, J. (2021). A study of optimal specifications for light shelves with photovoltaic modules to improve indoor comfort and save building energy. International Journal of Environmental Research and Public Health, 18(5), p. 1-23. https:// doi.org/10.3390/ijerph18052574

Lim, Y.W., Heng, C.Y.S. (2016). Dynamic internal light shelf for tropical daylighting in high-rise office buildings. Building and Environment 106, p. 155-166. https://doi.org/10.1016/j.buildenv.2016.06.030

Lim, Y.W., Kandar, M.Z., Ahmad, M.H., Ossen, D.R., Aminatuzuhariah, M.A. (2012) Building facade design for daylighting quality in typical government office building. Building and Environment 57, p. 194-204. https://doi.org/10.1016/j.buildenv.2012.04.015

Lim, Y.W. (2019). Tropical Daylighting for Working Environment. UTM Press, Skudai, Malaysia.

Mehta, P., Zhang, X., Thomas, R., Jadhav, N., Lee, J., Conaghan, C., Rawte, R. (2017). Harvesting 3D multiphysics modeling techniques for smart and sustainable university campus. Energy Procedia 143, p. 851-858. https://doi.org/10.1016/j.egypro.2017.12.773

Motamed, A., Bueno, B., Deschamps, L., Kuhn, T.E., Scartezzini, J.L. (2020). Self-commissioning glare-based control system for integrated venetian blind and electric lighting. Building and Environment 171, p. 106642. https://doi.org/10.1016/j.buildenv.2019.106642

Muhs, J.D. (2000). Design and analysis of hybrid solar lighting and full-spectrum solar energy system. Proceedings of American Solar Energy Society “Solar2000 Conference”, p. 229-237.

Obradovic, B., Matusiak, B.S. (2020). Daylight autonomy improvement in buildings at high latitudes using horizontal light pipes and light-deflecting panels. Solar Energy 208, p. 493-514. https://doi.org/10.1016/j.solener.2020.07.074

Ramesh, K.G., Ramachandraiah, A. (2021). Day lighting performance of a fractal window of first and second iterations. Materials Today: Proceedings 2021.

Sharifah, F.S.F., Sia, S.J. (2004). Sunlight control and daylight distribution analysis: the KOMTAR case study. Building and Environment 39, p. 713-717. https://doi.org/10.1016/j.buildenv.2003.12.009

Sharma, L., Ali, S.F., Rakshit, D. (2018). Performance evaluation of a top lighting light-pipe in buildings and estimating energy saving potential. Energy and Buildings 179, p. 57-72. https:// doi.org/10.1016/j.enbuild.2018.09.022

Wirz-Justice, A., Skene, D.J., Münch, M. (2020). The relevance of daylight for humans. Biochemical Pharmacology, p.114304. https://doi.org/10.1016/j.bcp.2020.114304

Wu, Y., Kämpf, J.H., Scartezzini, J.L. (2019). Automated 'Eyesight' Venetian blinds based on an embedded photometric device with real-time daylighting computing. Applied Energy, 252, p. 113317. https://doi.org/10.1016/j.apenergy.2019.113317

Zune, M., Pantua, C.A.J., Rodrigues, L., Gillott, M. (2020). A review of traditional multistage roofs design and performance in vernacular buildings in Myanmar. Sustainable Cities and Society, p. 102240. https://doi.org/10.1016/j.scs.2020.102240 